FORMATION Formation emploi

Revue française de sciences sociales

149 | Janvier-Mars 2020

Varia

\title{
Edito : professionnalisation : un long chemin pour certains...
}

Jean-Frédéric Vergnies

\section{(2) OpenEdition \\ Journals}

Édition électronique

URL : https://journals.openedition.org/formationemploi/7971

DOI : $10.4000 /$ formationemploi.7971

ISSN : 2107-0946

Éditeur

La Documentation française

Édition imprimée

Date de publication : 31 mars 2020

ISSN : 0759-6340

Référence électronique

Jean-Frédéric Vergnies, «Edito : professionnalisation : un long chemin pour certains... », Formation emploi [En ligne], 149 | Janvier-Mars 2020, mis en ligne le 03 avril 2020, consulté le 06 janvier 2022 URL : http://journals.openedition.org/formationemploi/7971; DOI : https://doi.org/10.4000/ formationemploi.7971

(c) Tous droits réservés 


\title{
Professionnalisation : un long chemin pour certains...
}

\author{
Jean-Frédéric Vergnies \\ Rédacteur en chef
}

Ce numéro souligne combien la professionnalisation est un processus complexe qui implique des acteurs multiples. Les articles de ce numéro montrent, chacun à leur manière et dans leur domaine, la potentielle fragilité de ce processus et sa dépendance à la fois au contexte socio-éducatif, à la conjoncture et à l'implication de certains acteurs.

Ainsi, les formations de technicien supérieur facilitent souvent l'accès à l'emploi ; pour autant, "le risque de quitter l'enseignement supérieur sans diplôme est aussi élevé que pour les jeunes sinscrivant à l'université», indique Fanette Merlin. L'échec en cours de préparation du brevet de technicien supérieur (BTS) constitue donc un défi pour la démocratisation du système d'enseignement supérieur.

Une autre filière, la formation en apprentissage, est souvent aussi prônée pour sa bonne insertion et son ouverture à un public large, dont certains en difficulté sociale ou scolaire. Pour autant, des jeunes peuvent rencontrer des problèmes qui les conduisent à résilier leur contrat d'apprentissage. Ainsi, à partir de l'exemple pourtant iconique de la Suisse, Isabelle Bosset, Barbara Duc et Nadia Lamamra nous invitent à questionner le système d'apprentissage, notamment dans sa capacité d'intégration, son rôle de facilitateur de la transition école-travail ou encore son adéquation, pas uniquement avec le système d'emploi, mais avant tout avec les aspirations des jeunes.

Ensuite, Magali Danner, Christine Guégnard et Olivier Joseph rappellent que près de deux millions de jeunes ne sont ni en étude, ni en emploi, ni en formation. L'amélioration de leur situation est donc une autre source de préoccupation sociale et éducative. En effet, mobilisant des données sur plus de vingt ans (enquêtes Génération du Céreq), leur recherche révèle que de nombreux facteurs expliquent la déconnexion de certains jeunes de l'emploi et de la formation. À la suite d'autres travaux, l'article rappelle combien le 
capital éducatif est le premier déterminant du risque de n'être ni en étude, ni en emploi, ni en formation, devant les autres facteurs sociaux, familiaux ou contextuels. Pour autant, ce risque comporte des enjeux encore plus importants pour les jeunes femmes.

À l'inverse, à l'autre extrémité du spectre de l'insertion, pour les professions du champ de la santé, là aussi, la professionnalisation ne va pas toujours de soi, notamment pour les professions en cours d'institutionnalisation. Au travers des travaux de Vivien Braccini, Franck Garnier \& Laurence Durat, le cas de l'ostéopathie révèle comment la professionnalisation des formateurs est nécessaire à la professionnalisation des jeunes étudiants.

Ainsi, ce numéro contribue à mettre en lumière des aspects souvent négligés et pourtant cruciaux du processus complexe de professionnalisation.

Bonne lecture à tous. 